\title{
Safety and outcome of external beam radiation and neutron brachytherapy in elderly patients with esophageal squamous cell cancer
}

\author{
Tao Li, MD*, Wei Zhang, MD*, Jiahua Lv, MD!, Huiming Liu, MD², Qifeng Wang, MD', Xitang Jia, MD², \\ Bo Liu, MD², Jinyi Lang, MD, PhD' \\ *Both authors contributed equally to this work. \\ 'Department of Radiation Oncology, Sichuan Cancer Hospital \& Institution, Sichuan Cancer Center, School of Medicine, University of Electronic \\ Science and Technology of China, Chengdu, 2Department of Radiation Oncology, Changzhi Cancer Hospital, Changzhi, China
}

\begin{abstract}
Purpose: The aim of this study was to retrospectively observe and analyze the long-term treatment outcomes of 191 elderly patients with esophageal squamous cell cancer (ESCC) who were treated with californium-252 (252Cf) neutron brachytherapy (NBT) in combination with external beam radiotherapy (EBRT).

Material and methods: From January 2002 to November 2012, 191 patients with ESCC underwent NBT in combination with EBRT. The total radiation dose to the reference point via NBT was 8-25 Gy-eq in two to five fractions with one fraction per week. The total dose via EBRT was 50-60 Gy, which was delivered over a period of 5 to 6 weeks with normal fractionation.

Results: The median survival time for the 191 patients was 23.6 months, and the 5-year rates for overall survival (OS) and local-regional control (LRC) were $28.7 \%$ and $54.2 \%$, respectively. The patients' age was a factor that was significantly associated with OS $(p=0.010)$, according to univariate analysis. The 5 -year OS (LRC) was $37.3 \%(58.6 \%)$ for patients aged $70-74$ years and $14.5 \%(47.9 \%)$ for patients aged $>74$ years $(p=0.010$ and $p=0.038)$. In multivariate analysis, age and clinical N stage were associated with OS and LRC ( $p=0.011$ [0.041] and $p=0.005$ [0.005]). From the time of treatment completion to the development of local-regional recurrence or death, $5(2.6 \%)$ patients experienced fistula and $15(7.9 \%)$ experienced massive bleeding. The incidence of severe late complications was related to older age $(p=0.027)$, higher NBT dose/fraction (20-25 Gy/5 fractions), and higher total dose (> $66 \mathrm{~Gy})$.

Conclusions: The clinical data indicated that NBT in combination with EBRT produced favorable local control and long-term survival rates for elderly patients with ESCC, and that the side effects were tolerable. Patient's age, clinical stage $\mathrm{N}$ status, and radiation dose could be used to select the appropriate treatment for elderly patients.

J Contemp Brachytherapy 2017; 9, 1: 36-43 DOI: https://doi.org/10.5114/jcb.2017.65839
\end{abstract}

Key words: californium-252, elderly patients, esophageal squamous cell cancer, neutron brachytherapy, late complication.

\section{Purpose}

In 2015, an estimated 477.9/100,000 cases of esophageal cancer (EC) were diagnosed in China, and approximately 375/100,000 people died from this disease [1,2]. In China, EC occurs in 50.3\% (161.3/320.8) of patients' aged $60-74$, and in $19.6 \%(62.9 / 320.8)$ of patients over 75 years of age in $[1,2]$. A radiation therapy oncology group study (RTOG 8501) demonstrated a survival benefit of the addition of platinum-based chemotherapy to radiation, compared to radiation alone for patients with nonsurgical EC [3,4]. RTOG 8501 only included about $23.1 \%(28 / 121)$ of elderly patients ( $\geq 70$ years). Thus, management of elderly patients with EC remains a therapeutic challenge, and the most relevant treatment modalities are still being debated. Although survival improvement has been observed over the past decade, EC treatment continues to be significantly influenced by age [5]. Moreover, it has also been reported that elderly patients have undergone less surgery, radiotherapy, and chemotherapy than younger patients [6]. To our knowledge, no specific data have been published regarding therapeutic strategies in elderly patients with EC. Despite progress in surgical practice, esophagectomy is associated with significant morbidity and mortality, and 75 years is often considered as the age limit for surgery [7]. External beam radiation therapy (EBRT) was an important treatment strategy for elderly patients. However, a few published results indicate that
Address for correspondence: 1. Qifeng Wang, MD, Department of Radiation Oncology, Sichuan Cancer Hospital \& Institution, Sichuan Cancer Center, School of Medicine, University of Electronic Science and Technology of China, NO 55, Renmin South Road, 610041 Chengdu, China, phone: +8602885420530 , fax: +86 02885420173, $₫$ e-mail: littlecancer@163.com; 2. Jinyi Lang, MD, PhD, 凶 e-mail: langjy610@163.com
Received: 25.08 .2016 Accepted: 02.01.2017 Published: 28.02.2017 
EBRT combined with brachytherapy in elderly patients with EC. Californium-252 $\left({ }^{252} \mathrm{Cf}\right)$ is a neutron-emitting radionuclide, and ${ }^{252} \mathrm{Cf}$-based neutron brachytherapy (NBT) has only been implemented in China very recently [8]. Neutron brachytherapy is a form of high linear energy transfer (LET) radiotherapy, which has been proven to be effective for treating intracavitary cancers of the cervix when used in combination with EBRT $[9,10]$.

We performed a retrospective cohort study of 191 patients older than 69 years who were diagnosed with locally advanced esophageal squamous cell cancer (ESCC), treated with radiation therapy. The main objective was to assess the overall survival and local control rates after EBRT plus neutron brachytherapy for elderly ESCC patients. We also evaluated the impact of age on treatment tolerance, prognostic factors, and patterns of failure.

\section{Material and methods}

\section{Patients}

From January 2001 until November 2012, a total of 191 consecutive patients older than 69 years with localized, advanced ESCC were referred to our department at the Changzhi Cancer Hospital for radiotherapy and ${ }^{252} \mathrm{Cf}$ NBT. The reasons were as follows: 30 patients were medically inoperable (6 patients were diabetic, 11 had chronic obstructive pulmonary disease, and 13 patients had a prior or concurrent malignancy); 34 patients rejected surgery; 76 patients were too old ( 75 years or older, 33 of 85 had T4 lesion); and 85 patients had unresectable lesions. Of these, 191 patients were treated with EBRT combined with brachytherapy. Patients with good performance status (at least able to care for himself or herself) and adequate hepatic, renal, and hematologic functions were selected for curative treatment. All the patients had squamous cell carcinoma. The patients' clinical stage was diagnosed by barium examination, endoscopy, endoscopic ultrasonography, or tumor histology.

\section{Radiotherapy}

Megavoltage radiation therapy units were used with a minimum source-to-axis distance of $100 \mathrm{~cm}$. The radiation field extended at least $3 \mathrm{~cm}$ superior and inferior to the tumor, with a lateral margin of at least $2 \mathrm{~cm}$. The field included the lesser curvature and bottom of stomach if the tumor invades gastroesophageal junction. The boost radiation field was the same length. Multi-field techniques were used to limit the maximum dose to the spinal cord to $\leq 45 \mathrm{~Gy}$. The radiation treatments were delivered 5 days/week at $2 \mathrm{~Gy} /$ fraction. The initial anterior-posterior parallel-opposed fields received $30 \mathrm{~Gy}$, and the offcord fields received 20-30 Gy, for a total dose of 40-54 Gy in 20-27 fractions in 4-5.5 weeks.

Neutron brachytherapy with a one-balloon applicator (Figure 1) [11] was used in conjunction with the ${ }^{252} \mathrm{Cf}$ LZH-1000 remote after-loading system (Linden Science and Technology Co., Shenzhen, China). The physical characteristics of the ${ }^{252} \mathrm{Cf}$ neutron, the characteristics of the applicator, and the process of NBT were described in detail by Liu $[12,13]$. The NBT dose was prescribed to the reference point, which was located at $10 \mathrm{~mm}$ from the center point of the source capsule in the transverse direction. Figure 1 is an X-ray image taken while the applicator and the simulator source were both inserted into the esophagus of a patient. The source applicator is a custom-made catheter, which not only allows the source wire to travel inside, but also includes a water balloon surrounding the source. The water balloon is $12 \mathrm{~cm}$ long, and its diameter can vary depending on the amount of water injected into it. The water balloon is an essential part of the applicator. For tumors that are eccentric with respect to the axis of the esophagus, the water balloon can be inflated accordingly to keep the source close to the tumor but away from the adjacent normal epithelium. In Figure 1, the water balloon can clearly be seen as it is filled with an X-ray contrast agent. The total NBT dose (to the reference point) given to each patient varied between 8 and 25 Gy-eq in two to five fractions, with 4-5 Gy-eq per fraction per week.

\section{Toxicity assessment and follow-up}

The patients were examined weekly during the EBRT. Weekly blood tests were obtained, and any admission for treatment-related complications was recorded. All adverse events were graded according to the National Cancer Institute's Common Terminology Criteria for Adverse Events, version 3.0 [14].

The patients usually underwent follow-up examinations every 3-4 months after the completion of treatment. Tumor response and nodal disease were evaluated with repeated computed tomography (CT) scans, barium swallow studies, and endoscopy.

\section{Statistical analysis}

The objectives of the study were to evaluate overall acute toxicity and local-regional control rates. Death from ESCC was considered as treatment failure in the survival analysis. Survival was calculated from the date of consultation until death or last follow-up evaluation. The pattern of failure (local and/or regional vs. distant) was defined as the first site of failure. The time to first failure, time to any local failure, and time to any distant metastases were calculated from the date of consultation. Local and regional recurrence included the primary tumor and regional lymph nodes. Overall survival and local-regional control were estimated using the Kaplan-Meier method. The parameters were also analyzed by multivariate analysis using the Cox regression model. Pearson's $\chi^{2}$ test was used to assess measures of association in the frequency data. A value of $p<0.05$ was considered statistically significant.

\section{Results}

\section{Patients' characteristics and treatments}

Age of the ESCC patients who were treated with radiation therapy (NBT and EBRT) ranged from 70 to 84 years (median: 75 years). There were 115 patients aged 70-74, and 76 patients aged $>74$ years. The cancer stages were 
categorized according to the $6^{\text {th }}$ edition of the AJCC Cancer Staging Manual, with 72 patients categorized as stage IIA, 10 patients categorized as stage IIB, and 109 patients were categorized as stage III. The detailed patient data and log-rank test are provided in Table 1.
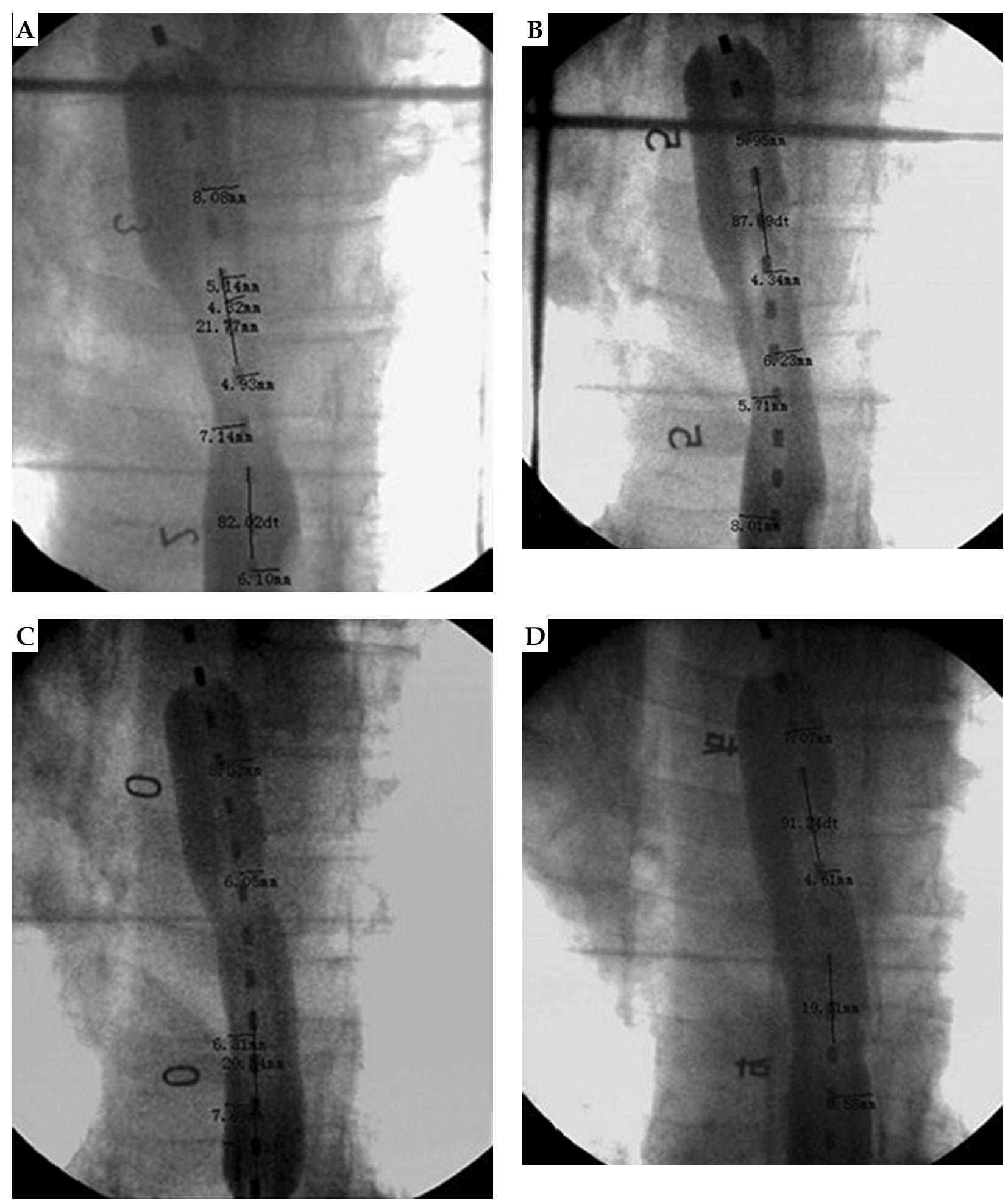

Fig. 1. Images (A-D) showing a 75 years' male patient, middle site esophageal squamous cell cancer. The length of primary tumor is $6 \mathrm{~cm}$. The tumor regression conditions before each of the four neutron brachytherapy treatments under an X-ray treatmentplanning simulator from A-D

\section{Prognostic factors for overall survival and local-regional control}

The duration of follow-up ranged from 6 to 106 months (median: 30.4 months). The median survival time for the 191 patients was 23.6 months, and the 1-, 2-, 3-,

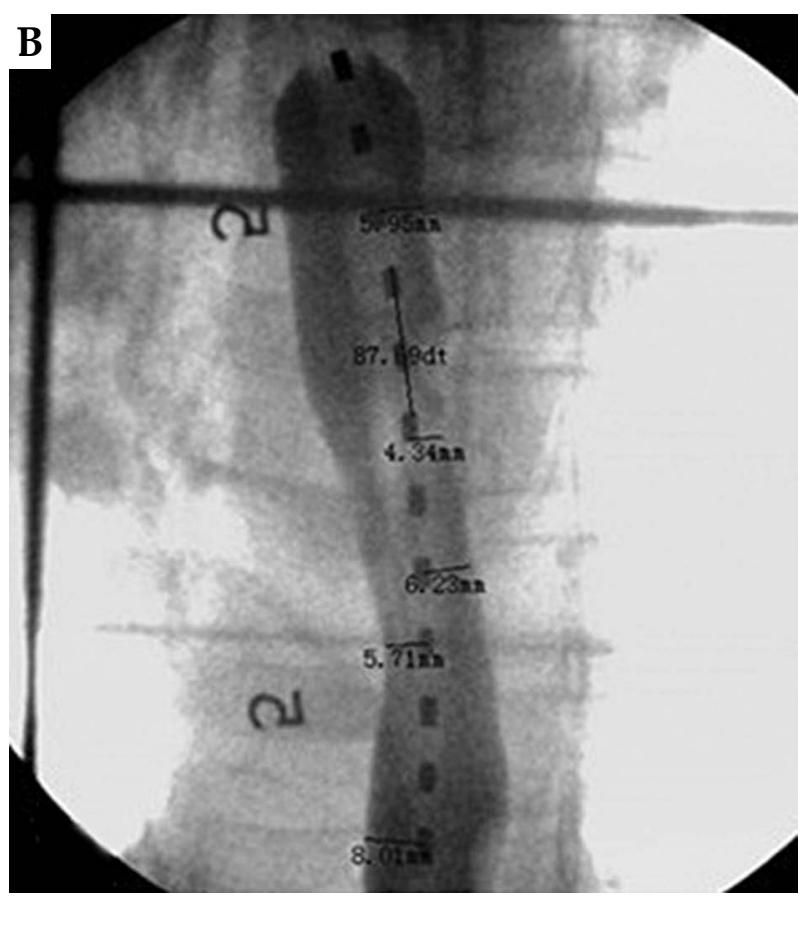


Table 1. Patient and tumor characteristics

\begin{tabular}{|c|c|c|c|c|}
\hline Characteristics & Total (\%) & $70-74$ years (\%) & $>74$ years $(\%)$ & $p$ value \\
\hline Gender & & & & 0.550 \\
\hline Male & $103(53.9)$ & $60(52.2)$ & $43(56.5)$ & \\
\hline Female & $88(46.1)$ & $55(47.8)$ & $33(43.5)$ & \\
\hline KPS & & & & 0.001 \\
\hline$\geq 80$ & $90(47.1)$ & $65(56.5)$ & $25(32.9)$ & \\
\hline 70 & $101(52.9)$ & $50(43.5)$ & $51(67.1)$ & \\
\hline The length & & & & 0.029 \\
\hline$\leq 5.0 \mathrm{~cm}$ & $99(51.8)$ & $67(58.3)$ & $32(42.1)$ & \\
\hline$>5.0 \mathrm{~cm}$ & $92(48.2)$ & $48(41.7)$ & 44 (57.9) & \\
\hline Tumor location & & & & 0.079 \\
\hline Upper & $51(26.7)$ & $37(32.2)$ & 14 (18.4) & \\
\hline Middle & $123(64.4)$ & $67(58.3)$ & $56(73.7)$ & \\
\hline Lower & $6(7.9)$ & $11(9.5)$ & $6(7.9)$ & \\
\hline T stage & & & & 0.098 \\
\hline $\mathrm{T} 2$ & $40(20.9)$ & $29(25.2)$ & 11 (14.5) & \\
\hline T3 & $66(34.6)$ & 34 (29.6) & $32(42.1)$ & \\
\hline T4 & $85(44.5)$ & $52(45.2)$ & $33(43.4)$ & \\
\hline N stage & & & & 0.279 \\
\hline NO & 109 (57.1) & $62(53.9)$ & $47(61.8)$ & \\
\hline $\mathrm{N} 1$ & $82(42.9)$ & $53(46.1)$ & $29(38.2)$ & \\
\hline $6^{\text {th }}$ AJCC stage & & & & 0.810 \\
\hline Ila & $72(30.7)$ & $43(37.4)$ & $29(38.2)$ & \\
\hline $11 \mathrm{~b}$ & $10(5.0)$ & $7(6.1)$ & $3(3.9)$ & \\
\hline III & $109(64.3)$ & $65(56.5)$ & 44 (57.9) & \\
\hline RT dose & & & & 0.047 \\
\hline$\leq 66$ Gy & 167 (87.4) & $105(91.3)$ & $62(81.6)$ & \\
\hline$>66 \mathrm{~Gy}$ & $24(12.6)$ & $10(8.7)$ & $14(18.4)$ & \\
\hline
\end{tabular}

$R T$ - radiotherapy alone, $O S$ - overall survival rate, $L C R$ - local control rate

and 5-year rates for overall survival (OS) were 68.5\%, $48.2 \%, 40.3 \%$, and $28.7 \%$, respectively. The 1-, 2-, 3-, and 5 -year rates for local-regional control (LRC) were $82.2 \%$, $67.0 \%, 61.8 \%$, and $54.2 \%$, respectively.

We used the following nine factors for the univariate analysis of survival rates and local control rate: sex, age, Karnofsky score (KPS), tumor location, tumor length, tumor T stage, nodal stage, clinical stage, and radiation dose. Among them, three (age, tumor length, and clinical $\mathrm{N}$ stage) were found to have relevance to OS ( $p=0.010$, $p=0.016$, and $p=0.009$, respectively). Age, clinical N stage, and radiation dose were factors that were significantly related to LRC ( $p=0.038, p=0.014, p=0.014$, respectively). In the univariate analysis, the 5-year OS (LRC) was 37.3\%
(58.6\%) for patients aged 70-74 years, and 14.5\% (47.9\%) for patients aged $>74$ years $(p=0.010$ and $p=0.038$, respectively, Figure $2 \mathrm{~A}$ and $\mathrm{B}$ ). In multivariate analysis, age and clinical $\mathrm{N}$ stage were associated with OS and LRC $(p=0.011[0.041]$ and $p=0.005$ [0.005]) (Table 2).

\section{Patterns of failure}

At the time of the analysis, 80 patients were alive and free of disease, and 5 patients were alive with disease evolution. Distant metastases occurred in 37 patients (19.4\%). The median time to developing distant metastases was 8.9 months. The main sites of distant metastases were the lung $(n=9)$, liver $(n=5)$, brain $(n=2)$, and bones $(n=8)$. In 14 patients, metastases developed in more than one organ. 
A

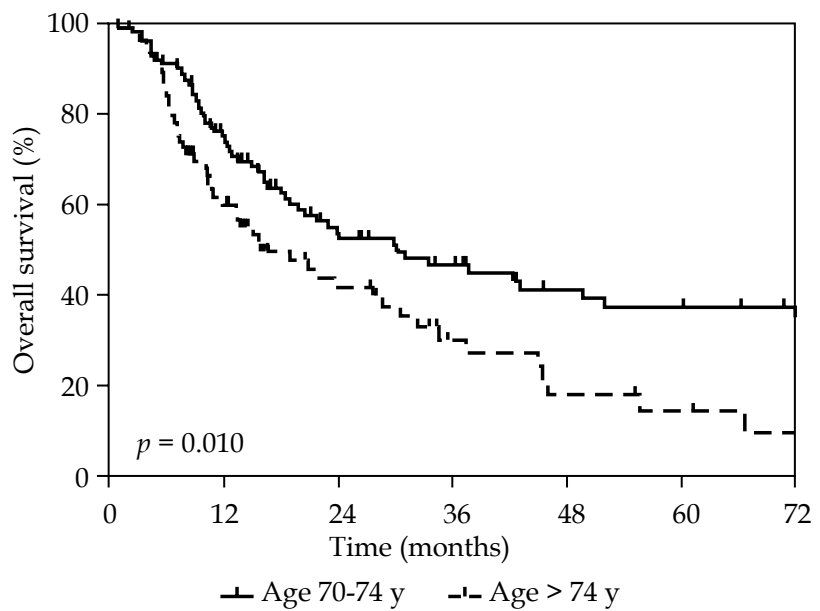

B

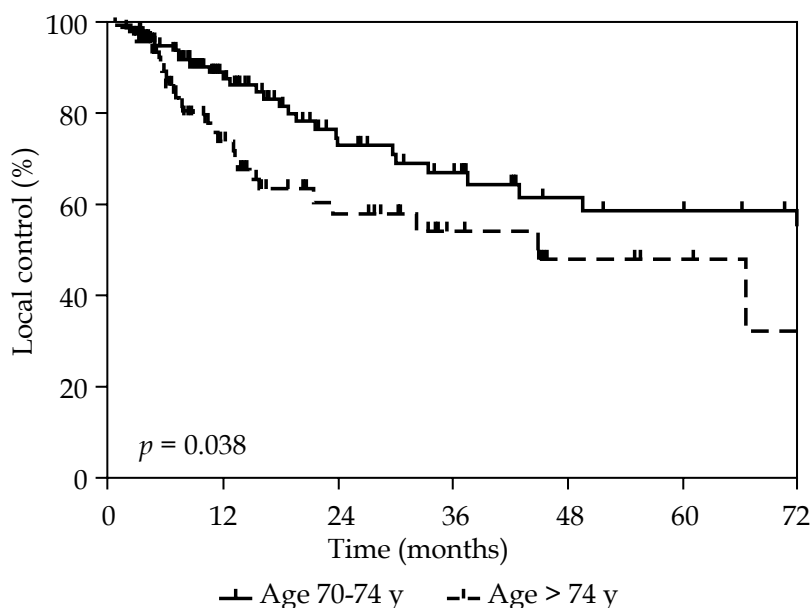

Fig. 2. Comparison of the overall survival rate (A), and local control rate (B) between the two treatment groups

Table 2. Results of multivariate Cox regression analysis of overall survival and local-regional control

\begin{tabular}{lcccccc} 
& \multicolumn{3}{c}{ Overall survival } & \multicolumn{3}{c}{ Local-regional control } \\
\cline { 2 - 7 } & $p$ value & HR & $95 \% \mathrm{Cl}$ & $p$ value & $\mathrm{HR}$ & $95 \% \mathrm{Cl}$ \\
\hline Age: $70-74$ (vs. $>$ 74) & 0.011 & 1.617 & $1.128-2.476$ & 0.041 & 1.756 & $1.024-3.013$ \\
\hline Tumor length: $\leq 5 \mathrm{~cm}$ (vs. > 5 cm) & 0.124 & 1.357 & $0.920-2.000$ & 0.570 & 1.165 & $0.687-1.976$ \\
\hline cN stage: N0 (vs. N1) & 0.005 & 1.762 & $1.185-2.619$ & 0.005 & 2.197 & $1.276-3.782$ \\
\hline Total dose: $\leq 66$ Gy (vs. > 66 Gy) & 0.076 & 1.569 & $0.955-2.580$ & 0.011 & 2.244 & $1.207-4.171$
\end{tabular}

$\mathrm{Cl}$-confidence interval, $H R$ - hazard ratio, $c$-clinical

Additionally, 15 patients died of mixed causes, including pneumonia, cerebral hemorrhage, and heart infarction. Local-regional recurrence occurred in 59 (59/191, 30.9\%) patients, with $9 / 59(15.3 \%)$ occurrences outside the radiation fields and 50/59 (84.7\%) occurrences inside the radiation fields. Additionally, $7 / 49(14.3 \%)$ had primary tumor recurrences. None of those patients underwent salvage surgery.

\section{Treatment toxicity}

In terms of acute toxicity, no perforations were observed during this treatment period. In total, 88 (46.1\%) patients developed a grade 2 hematologic toxicity. Dysphagia was relieved after the second or third NBT treatment in $87 \%$ of the patients, and a temporary feeding tube was not required in most of the patients. Grade $\geq 2$ esophagitis, expressed by clinical odynophagia, was observed in 64 cases $(33.5 \%)$, and it was managed with the early introduction of $\mathrm{H}_{2}$ blockers and surface anesthesia at the initiation of the NBT. In total, eight (4.2\%) patients had grade $\geq 2$ irradiation dermatitis. From the time of treatment completion to the development of local-regional recurrence or death, $5(2.6 \%)$ and 15 (7.9\%) patients experienced fistula and massive bleeding, respectively. The median time of incidence was 7.0 (3.7-55.7) months for fistula and 9.5 (3.2-90.9) months for bleeding. As shown in Table 3, the incidence of severe, late complications was related to older age $(p=0.027)$, higher NBT dose/fraction (20-25 Gy/5F), and higher total dose (> $66 \mathrm{~Gy})$. In total, $68.5 \%$ of the patients resumed normal swallowing, while $4.2 \%$ had some residual dysphagia (non-malignant) requiring intermittent dilatation.

\section{Discussion}

To our knowledge, this is the first reported clinical experience of the treatment using NBT and EBRT for elderly patients with ESCC. The safety and efficacy of this comprehensive treatment appear promising. We also found that, firstly, NBT + EBRT is safe and beneficial in terms of local control in the radical treatment of elderly patients with ESCC, and secondly, the OS rate was significantly increased, and the late complication rate was significantly decreased in patients aged 70-74 years compared to that of patients aged $>74$ years. During the treatment period, no severe treatment related complication occurred.

Definitive conformal radiotherapy (CRT) is considered a feasible nonsurgical treatment in patients with a locally advanced EC, and approximately a 50-65\% clinical complete response rate, 17-26 months of median overall survival, and $30-40 \%$ 2-year survival rate $[15,16,17]$. In the current study, the OS was similar to the results of prior studies, though without chemotherapy $[15,16,17]$.

We believe that there are at least two factors that made the ${ }^{252} \mathrm{Cf}$-based NBT more effective for local tumor than 
Table 3. Treatment toxicity and the sites of the first failure according to different age groups

\begin{tabular}{|c|c|c|c|}
\hline Characteristics & $70-74$ years $(n=115)$ & $>74(n=76)$ & $p$ value \\
\hline \multicolumn{4}{|c|}{ Acute toxicity (Events of any grade during treatment - no. of patients; Events of grade $\geq 2$ ) } \\
\hline Esophagitis & $63(54.8 \%)$ & $47(61.8 \%)$ & 0.631 \\
\hline Skin complications & $17(14.8 \%)$ & $16(21.1 \%)$ & 0.262 \\
\hline Pulmonary complications & $5(4.3 \%)$ & $3(3.9 \%)$ & 0.892 \\
\hline Leukopenia & $52(45.2 \%)$ & $36(47.4 \%)$ & 0.982 \\
\hline Neutropenia & $40(34.7 \%)$ & $23(30.3 \%)$ & 0.849 \\
\hline Thrombocytopenia & $13(11.3 \%)$ & $6(7.9 \%)$ & 0.441 \\
\hline \multicolumn{4}{|l|}{ Late toxicity } \\
\hline Esophageal fistulas & $1(0.9 \%)$ & $4(5.3 \%)$ & 0.063 \\
\hline Massive bleeding & $5(4.3 \%)$ & $10(13.2 \%)$ & 0.027 \\
\hline \multicolumn{4}{|l|}{ The sites of the first failure in the whole group } \\
\hline Local-regional failure & $32(27.8 \%)$ & $27(35.5 \%)$ & 0.045 \\
\hline In field & $29(25.2 \%)$ & $21(27.6 \%)$ & 0.134 \\
\hline Out field & $3(2.6 \%)$ & $6(7.9 \%)$ & 0.032 \\
\hline Distant metastasis & $21(18.3 \%)$ & $14(13.1 \%)$ & 0.128 \\
\hline Lung & $4(3.5 \%)$ & $5(6.6 \%)$ & 0.483 \\
\hline Liver & $1(0.9 \%)$ & $1(1.3 \%)$ & 0.393 \\
\hline Bone & $5(4.3 \%)$ & $3(3.9 \%)$ & 0.483 \\
\hline Brain & $1(0.9 \%)$ & $1(1.3 \%)$ & 0.552 \\
\hline$\geq 2$ Metastasis sites & $10(3.6 \%)$ & $4(5.2 \%)$ & 0.726 \\
\hline $\begin{array}{l}\text { Not otherwise specified (disease of heart, head blood-ves- } \\
\text { sel, pneumonia, second tumor) }\end{array}$ & $5(4.3 \%)$ & $6(17.9 \%)$ & 0.690 \\
\hline
\end{tabular}

Table 4. Comparative toxicity rates, overall survival and local control of selected series

\begin{tabular}{|c|c|c|c|c|c|c|}
\hline Factor & $\begin{array}{l}\text { Hishikawa } \\
\text { et al. [20] }\end{array}$ & $\begin{array}{l}\text { Flores } \\
\text { et al. [21] }\end{array}$ & $\begin{array}{l}\text { Hareyama } \\
\text { et al. [22] }\end{array}$ & $\begin{array}{l}\text { Sharma } \\
\text { et al. [23] }\end{array}$ & RTOG9207 [19] & Present study* \\
\hline No. of pts. & 148 (66" pts) & 145 & 161 & 100 & 50 & 191 \\
\hline BT Gy/fraction & $12 / 2$ & $15 / 1$ & $15-20 / N S$ & $15-20 / 1$ & $15 / 3$ & $12-25 / 2-6$ \\
\hline ERT Gy/fraction & $60 / 30$ & $40 / 15$ & $47-70 / 25-35$ & $50 / 28$ & 50 & $40-60$ \\
\hline $\mathrm{CT}$ (pts) & No & No & No & Yes & Yes & 191/191 \\
\hline Fistula (\%) & 5.3 & 5 & 1.2 & 12 & 12 & 2.6 \\
\hline Bleeding (\%) & 0 & 11 & 0 & 4 & NS & 7.9 \\
\hline Ulcer (\%) & 7.1 & NS & 3 & 29 & NS & 2.6 \\
\hline Stricture (\%) & 10 & 35 & 3 & 16 & 4 & 4.2 \\
\hline Death rate (\%) & 3 & 0.6 & 0 & 4 & 8 & 0 \\
\hline OS (\%) & $\begin{array}{l}37(2 \mathrm{y}) \\
\left(66^{\#} \text { pts }\right)\end{array}$ & $\begin{array}{l}26(2 y) \\
19(3 y)\end{array}$ & $\begin{array}{l}43.3 \text { - stage I (5 y), } \\
21.1 \text { - stage II }(5 \mathrm{y})\end{array}$ & $23(5 \mathrm{y})$ & $48(1 \mathrm{y})$ & $36.3(3 \mathrm{y})$ \\
\hline LC (\%) & $\begin{array}{l}64(2 \mathrm{y}) \\
\left(66^{\#} \mathrm{pts}\right)\end{array}$ & NS & $31.7 \%(5 y)$ & NS & $58(1 \mathrm{y})$ & $75.6(3 y)$ \\
\hline
\end{tabular}

CT - chemotherapy, BT - brachytherapy, ERBT - external beam radiotherapy, Pts - patients, y - years, NS - not stated, OS - overall survival, "\#L - limited disease, LC - local control

*Brachytherapy applied between EBRT 
chemotherapy regimens, particularly in the treatment of locally advanced ESCC. The first factor is related to the high-LET nature of fission neutrons, which made them much more effective (compared to the low-LET X-ray) in killing the hypoxic tumor cells in the locally advanced cancers. The second factor is related to the fact that water is an effective neutron attenuator that can be conveniently injected into the source applicator during treatment to reduce the neutron dose to the nearby normal tissue. Because there is a significant difference in the elasticities of normal tissue and tumor tissue, the proper injection of water into the source applicator can effectively push away the nearby normal tissue while still keeping the tumor tissue close to the source.

Tougeron reported that age $>74$ years was associated with worse creatinine clearance $(p<0.01)$ and greater chemotherapy dose reduction at treatment onset due to age $(p<0.01)$, but this had no influence on total CRT dose, or OS [18]. In the current study, the incidence of late severe complications was significantly related to the factors of higher total dose and NBT dose. In addition to the dose factors, the patients' age also significantly increased the incidence of relevant, late complications. While the normally expected side effects (shown in Table 4) seem to be quite acceptable, the number of deaths ( $n=20$ or $10.5 \%)$ resulting from fistula, hematemesis, and hemoptysis is high. This may be linked to the late effect of radiation damage, as fatal esophagitis of fistula cases were also observed in the RTOG 92-07 trial where the ${ }^{192} \mathrm{Ir}$-based high-dose-rate boost dose of $15 \mathrm{~Gy}$ in 3 weekly fractions was deemed to be too high [19]. However, they could also have been caused by local recurrences of the cancer. Further CT review is needed to compare the pretreatment tumor length, esophageal tumor wall thickness, and association of tumor with surrounding normal structures with subsequent fistula formation.

The major limitation of our study was that the retrospective analysis might have been based on incomplete medical records. Others restrictions were that the study was conducted in a single institution, small sample size, and the lack of predefined factors determining treatment decisions, which were based only on evaluations by the referral doctor and members of a multidisciplinary team. It should nonetheless be recalled that the aim of the study was to retrospectively identify the parameters to be associated with the key therapeutic decision.

\section{Conclusions}

Our results suggest that elderly patients with ESCC could benefit from NBT + EBRT without major toxicities. Patient's age, clinical stage $\mathrm{N}$ status, and radiation dose could be used to select the appropriate treatment in an elderly patient.

\section{Acknowledgments}

The authors gratefully thank Professor C.K. Chris Wang for excellent assistance. This work was supported by Sichuan Province, the selected excellent projects for foundation from the science and technology projects in year 2016.

\section{Disclosure}

Authors report no conflict of interest.

\section{References}

1. Zeng H, Zheng R, Zhang $S$ et al. Esophageal cancer statistics in China, 2011: Estimates based on 177 cancer registries. Thorac Cancer 2016; 7: 232-237.

2. Chen W, Zheng R, Baade PD et al. Cancer statistics in China, 2015. CA Cancer J Clin 2016; 66: 115-132.

3. Cooper JS, Guo MD, Herskovic A et al. Chemoradiotherapy of locally advanced esophageal cancer: long-term follow-up of a prospective randomized trial (RTOG 85-01). Radiation Therapy Oncology Group. JAMA 1999; 281: 1623-1627.

4. Herskovic A, Martz K, al-Sarraf M et al. Combined chemotherapy and radiotherapy compared with radiotherapy alone in patients with cancer of the esophagus. N Engl J Med 1992; 326: 1593-1598.

5. Bouvier AM, Launoy G, Lepage C et al. Trends in the management and survival of digestive tract cancers among patients aged over 80 years. Aliment Pharmacol Ther 2005; 22: 233-241.

6. Steyerberg EW, Neville B, Weeks JC et al. Referral patterns, treatment choices, and outcomes in locoregional esophageal cancer: a population-based analysis of elderly patients. J Clin Oncol 2007; 25: 2389-2396.

7. Law S, Wong KH, Kwok KF et al. Predictive factors for postoperative pulmonary complications and mortality after esophagectomy for cancer. Ann Surg 2004; 240: 791-800.

8. Wang CKCh. Progress in californium-252 neutron brachytherapy. In: Brachytherapy. Kishi K (ed.). InTech, Rijeka 2012.

9. Maruyama Y, van Nagell JR, Yoneda J et al. A review of californium-252 neutron brachytherapy for cervical cancer. Cancer 1991; 68: 1189-1197.

10. Lei X, Qian CY, Qing Y, et al. Californium-252 brachytherapy combined with external-beam radiotherapy for cervical cancer: long-term treatment results. Int J Radiat Oncol Biol Phys 2011; 81: 1264-1270.

11. Buzurovic IM, Hansen JL, Bhagwat MS et al. Clinical implementation of a novel applicator in high-dose-rate brachytherapy treatment of esophageal cancer. J Contemp Brachytherapy 2016; 8: 319-325.

12. Liu H, Wang $Q$, Jia $X$ et al. Early-stage esophageal squamous cell carcinoma treated with californium-252 neutron brachytherapy: clinical report on 16 cases. Tumori 2013; 99: 172-175.

13. Liu H, Wang Q, Wan X et al. Californium-252 neutron brachytherapy combined with external beam radiotherapy for esophageal cancer: long-term treatment results. Brachytherapy 2014; 13: 514-521.

14. Common Terminology Criteria for Adverse Events VA, 2006: Available at: http://ctep.cancer.gov/protocolDevelopment/ electronic_applications/docs/ctcaev3.pdf. Assessed: 5 October 2009.

15. Bedenne L, Michel P, Bouché O et al. Chemoradiation followed by surgery compared with chemoradiation alone in squamous cancer of the esophagus: FFCD 9102. J Clin Oncol 2007; 25: 1160-1168.

16. Stahl M, Stuschke M, Lehmann $N$ et al. Chemoradiation with and without surgery in patients with locally advanced squamous cell carcinoma of the esophagus. J Clin Oncol 2005; 23: 2310-2317.

17. Michel P, Adenis A, Di Fiore F et al. Induction cisplatin-irinotecan followed by concurrent cisplatin-irinotecan and radiotherapy without surgery in oesophageal cancer: multicenter phase II FFCD trial. Br J Cancer 2006; 95: 705-709. 
18. Tougeron D, Di Fiore FD, Thureau S et al. Safety and outcome of definitive chemoradiotherapy in elderly patients with oesophageal cancer. Br J Cancer 2008; 99: 1586-1592.

19. Gaspar LE, Qian Ch, Kocha WI et al. A phase III study of external beam radiation, brachytherapy and concurrent chemotherapy in localized cancer of the esophagus (RTOG 92-07): preliminary toxicity report. Int J Radiat Oncol Biol Phys 1997; 37: 593-599.

20. Hishikawa Y, Kurisu K, Taniguchi M et al. High-dose-rate intraluminal brachytherapy for esophageal cancer: 10 years' experience in Hyogo College of Medicine. Radiother Oncol 1991; 21: 107-114.

21. Flores AD, Nelems B, Evans $\mathrm{K}$ et al. Impact of new radiotherapy modalities on the surgical management of cancer of the esophagus and cardia. Int J Radiat Oncol Biol Phys 1989; 17: 937-944.

22. Hareyama M, Nishio M, Kagami $Y$ et al. Intracavitary brachytherapy combined with external-beam irradiation for squamous cell carcinoma of the thoracic esophagus. Int J Radiat Oncol Biol Phys 1992; 24: 235-240.

23. Sharma V, Agarwal J, Dinshaw K et al. Late esophageal toxicity using a combination of external beam radiation, intraluminal brachytherapy and 5-fluorouracil infusion in carcinoma of the esophagus. Dis Esophagus 2000; 13: 219-225. 